\title{
Low Cycle Fatigue Properties of Notched Specimen for 022Cr17Ni12Mo2 Stainless Steel
}

\author{
Jingying Tan ${ }^{1, a}$, Qizhou Wü, b, Ran Sun ${ }^{2, c}$, Dan Jin ${ }^{2, d *}$ \\ ${ }^{1}$ School of Mechanical Engineering, Hunan Institute of Science and Technology, Yueyang, 410000, \\ China; \\ ${ }^{2}$ School of Energy and Power Engineering, Shenyang University of Chemical Technology, \\ Shenyang 110142, China \\ ajingyingtan@163.com, b252512782@qq.com, ${ }^{c} 503247071 @ q q . c o m,{ }^{d}$ jindan76@163.com \\ *The corresponding author
}

Keywords: 022Cr17Ni12Mo2 stainless steel; Low cycle fatigue; Notched specimen; Cyclic hardening; Hysteresis loop properties

\begin{abstract}
A series of low cycle fatigue tests under stress control were conducted for the smooth and notched specimen of $022 \mathrm{Cr} 17 \mathrm{Ni} 12 \mathrm{Mo} 2$ stainless steel. The ratio of fatigue strength of smooth specimen to notched specimen decreases with decrease in fatigue life. The notched effect is more significant at lower stress level. The cyclic additional hardening is observed for the smooth and notched specimen at all test conditions. The cyclic hardening amount is larger for notched specimen than those for smooth specimen at the same stress levels.
\end{abstract}

\section{Introduction}

Type 316L austenitic stainless steel has been widely used in components in nuclear reactors, international thermonuclear experimental reactor, Generation-IV nuclear reactors, and so on [1-2]. It processes good tensile, creep, fatigue and creep-fatigue strength, fracture toughness and fabric ability at high temperatures [3]. In a design of liquid metal cooled fast breeder reactor components, resistance to low cycle fatigue damage is essential, because the components are often subjected to repeated cyclic thermal stresses resulting from temperature variations during start-ups, shut-downs and power transitions. Therefore, LCF damage is one of the dominant failure modes, requiring a safe and efficient design and life analysis of LMFBR components [4-5].

Roy et al. [6] studied cyclic hardening properties of $316 \mathrm{~L}(\mathrm{~N})$ at room temperature and performed elastic-plastic finite element analysis to obtain hysteresis loops under repeated loadings. They estimated LCF lives based on the analyzed plastic strain energy dissipation. Pham et al. [7-8] showed the cyclic deformation characteristic of the austenitic stainless steel being composed with cyclic hardening, stress saturation and cyclic softening, and they discussed these three stages in relation with different microstructure developments. Ueno et al. [9] reported the substantial improvement in monotonic and cyclic strength for austenitic 316L stainless steel by nanostructuring. Some studies discussed on the corrosion of 316L stainless steel [10, 11].

In this investigation, a series of tensile tests and low cycle fatigue tests for stress ratio $\mathrm{R}=0$ under stress control were conducted for the smooth and notched specimens of $022 \mathrm{Cr} 17 \mathrm{Ni} 12 \mathrm{Mo} 2$ stainless steel. The cyclic stress-strain curves and stress-life curves were gained. The fatigue property for this material was discussed.

\section{Test Procedure}

Specimen Preparation. Test material used in this study was $022 \mathrm{Cr} 17 \mathrm{Ni} 12 \mathrm{Mo} 2$ stainless steel, cold rolling state. The material property are followed, yield strength $342 \mathrm{MPa}$, ultimate strength $607 \mathrm{MPa}$, reduction of area $68 \%$, and elasticity modulus $200 \mathrm{GPa}$. The plate specimens used in low cycle fatigue tests for smooth and notched specimen are shown in Fig 1 and Fig 2. The thickness is $1 \mathrm{~mm}$. 
The semicircle notch was chosen for the tests, $\mathrm{R}=0.25 \mathrm{~mm}$. The elastic stress concentration factors is $K_{T}=2.4$.

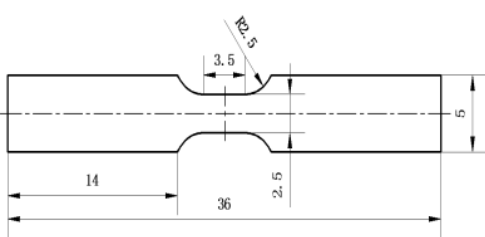

Figure 1 Smooth plate specimen (mm)

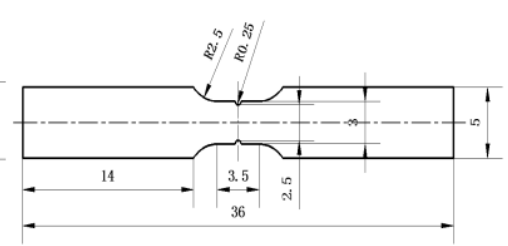

Figure 2 Notched plate specimen (mm)

Test Process. EUT-1020 was used for low cycle fatigue tests under uniaxial loading at room temperature. The tensile tests were carried for smooth and notched specimens and the load velocity was $0.8 \times 10^{-3} \mathrm{KN} / \mathrm{s}$. The pull-pull fatigue tests were carried under stress control for smooth and notched specimens. The waveform was triangular. The minimum load was set zero (i.e., stress ratio $\mathrm{R}=0$ ). The failure life was defined as fracture. Test conditions and fatigue test results for smooth and notched specimens are shown in Table 1.

Table 1 Test conditions and fatigue test results

\begin{tabular}{|c|c|c|c|c|}
\hline Serial number & $\mathrm{F}_{\max } / \mathrm{KN}$ & $\sigma_{\max } / \mathrm{MPa}$ & \multicolumn{2}{|c|}{ Fatigue life $\mathrm{N}_{\mathrm{f}} /$ cycle } \\
\cline { 3 - 5 } & & & Smooth specimen & Notched specimen \\
\hline No.1 & 1.4 & 564 & 2326 & 1368 \\
\hline No.2 & 1.3 & 518 & 4895 & 3240 \\
\hline No.3 & 1.2 & 480 & 7224 & 5393 \\
\hline No.4 & 1.1 & 442 & 10884 & 7582 \\
\hline No.5 & 1.0 & 400 & 27153 & 12338 \\
\hline No.6 & 0.9 & 360 & 37865 & 31696 \\
\hline No.7 & 0.8 & 320 & 46676 & 41868 \\
\hline No.8 & 0.7 & 282 & - & \\
\hline
\end{tabular}

\section{Test Results and Discussion}

S-N Curves. S-N curves for smooth and notched specimen are shown in Fig 3. It can be seen that the two curves for smooth and notched specimen are not parallel. The following approximate equations can be obtained based on the test results.

Smooth specimen

Notched specimen

$$
\begin{gathered}
\sigma_{m a}=219 .\left(\mathcal{R}_{f}\right)^{.01} \\
\sigma_{\max }=2343.5\left(N_{f}\right)^{-0.1901}
\end{gathered}
$$

Where $\sigma_{\max }$ is the maximum cyclic stress, $N_{f}$ is fatigue failure life.

The fatigue strength factor for notched specimen is gained, Equ.1 divided by the Equ.2

$$
K=0.935\left(\mathrm{~N}_{f}\right)^{0.0182}
$$




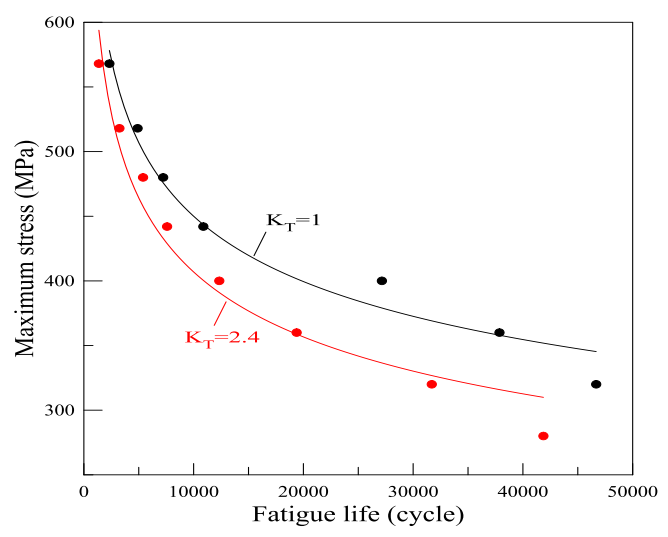

Figure 3. S-N curve

From Fig. 3 and Equ.3, the fatigue strength ratio is larger when the life is longer, vice versa. Fatigue will occur if the material is subjected to the alternating stress. There are two phases, crack initiation and crack propagation. The axial stress at the notch root is almost equivalent to the axial stress of smooth specimen before the crack initiation. In the process of crack propagation, however, the axial stress of the notched specimen will vary and the propagation lives are different between the smooth and notched specimen. The shorter fatigue life, i.e., higher stress, the ratio of the propagation life to the fatigue failure life is larger so the fatigue failure life is shorter and the fatigue strength ratio is less. Moreover, the plastic deformation will occur at higher cyclic stress and the stress will be redistributed. The notched effect is not more significant at higher stress level than lower stress level.

The Hysteresis Loop Properties. The hysteresis loops for the smooth and notched specimens under 442MPa are shown in Fig 4(a) and Fig 4(b). For two types of specimen, the curve is long and narrow, and sharper at both ends. In the fatigue process, the elastic deformation is dominated and the plastic strain is smaller. Cycle $80^{\text {th }}, 220^{\text {th }}$, and $2000^{\text {th }}$ are shown in Fig 4(a) and Fig 4(b). With increase in cycle, the hysteresis loop becomes smaller due to the cyclic hardening occurring. At the same stress level and cycle number, the hysteresis loop width of notched specimen is more than that of the smooth one. The plastic strain is larger and it can be attributed to the stress concentration.

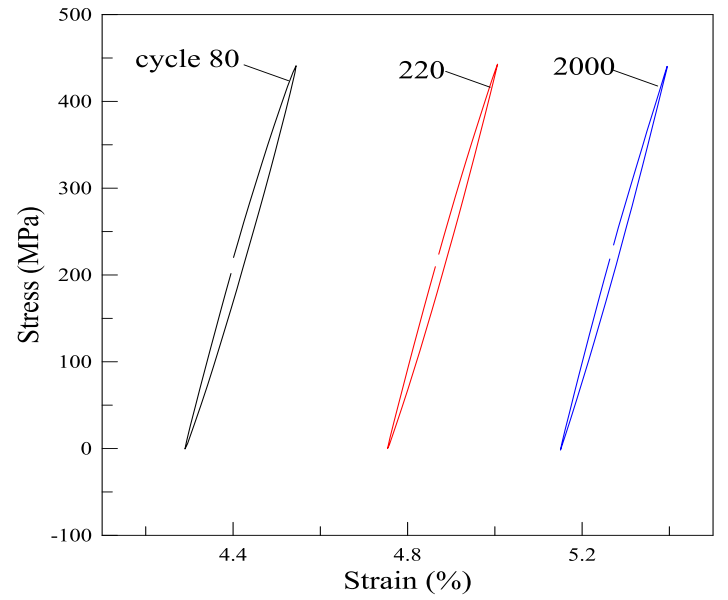

(a)

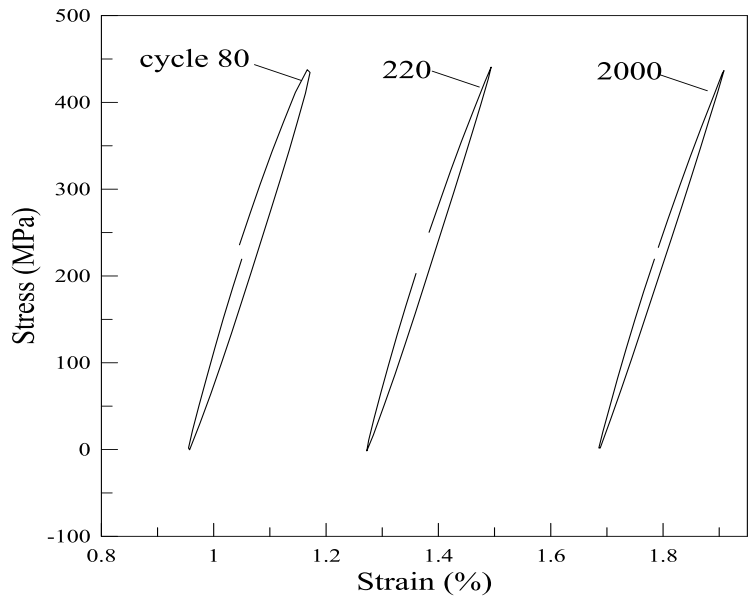

(b)

Figure 4. Hysteresis loops under 442MPa for
(a) smooth specimen
(b) notched specimen

Cyclic Hardening Behavior. The strain ranges of smooth and notched specimen at different stress levels are plotted in the Fig 5(a) and Fig 5(b). The cyclic hardening phenomena can be seen from each curve and this phenomenon is more significant at higher stress level. For smooth specimen, the strain ranges reach stabilization after 100 cycles. But for notched specimen, the cyclic 
stabilization is observed after 60 cycles. The variation amounts of the strain range from the first cycle to stabilization cycle are different in different test levels for smooth and notched specimen. At $0 \sim 320 \mathrm{MPa}$, the variation amounts of the strain range for notched specimen is $0.018 \%$, but $0.012 \%$ is for smooth specimen. The variation amplitudes are $0.019 \%$ for smooth specimen and $0.016 \%$ for notched specimen at $0 \sim 360 \mathrm{MPa}, 0.024 \%$ for smooth specimen and $0.020 \%$ for notched specimen at $0 \sim 442 \mathrm{MPa}$. From the comparison, it can be concluded that the variation amounts are larger at the same stress level for notched specimen than those for smooth specimen. The stress level can influence the notched specimen more significant than smooth specimen so the cyclic hardening phenomenon is more prominent for notched specimen for this material.

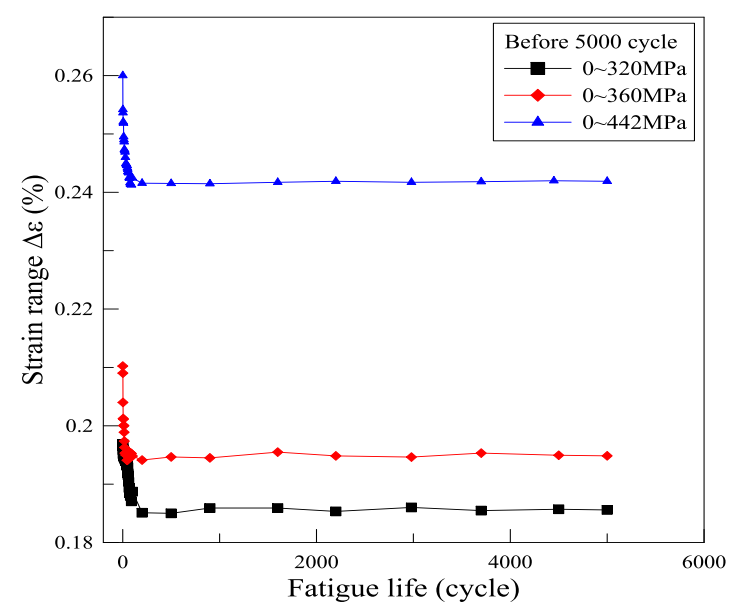

(a)

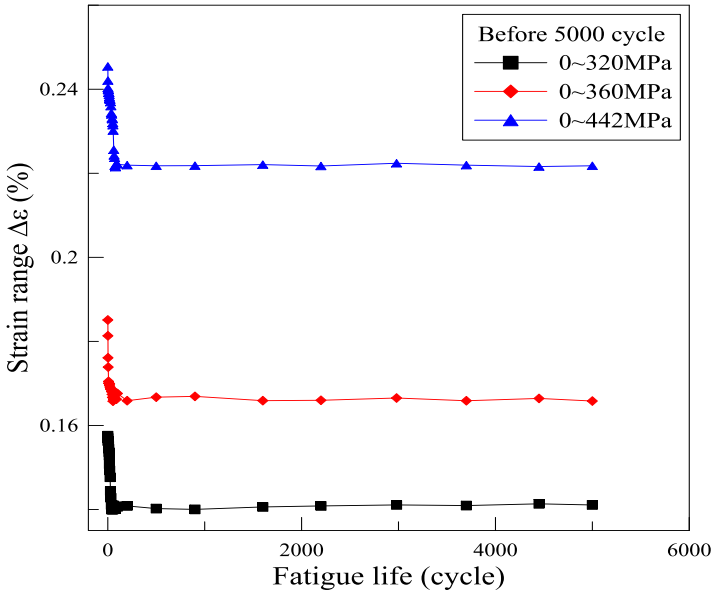

(b)

Figure 5. Strain range under different stress amplitude for

$\begin{array}{ll}\text { (a) smooth specimen } & \text { (b) notched specimen }\end{array}$

\section{Conclusion}

A series of low cycle fatigue tests under stress control were conducted for the smooth and notched specimen for $022 \mathrm{Cr} 17 \mathrm{Ni} 12 \mathrm{Mo} 2$ stainless steel. It can be concluded,

(1) The ratio of fatigue strength of smooth specimen to notched specimen decreases with decrease in fatigue life. The fatigue life decreases with increase in stress level for smooth specimen to notched specimen, however the decrease amount is more obvious at lower stress level.

(2) Comparison the hysteresis loop between the smooth specimen and notched specimen, the hysteresis loop is wider for the notched specimen than those of smooth specimen at the same stress level. The cyclic additional hardening is observed for the smooth and notched specimen at all test conditions. The cyclic hardening amount is larger for notched specimen than those for smooth specimen at the same stress levels.

\section{Acknowledgement}

The authors are grateful to the supports of the projects of National Natural Science of Foundation of China (Grant No.11102119) and Hunan Provincial Natural Science Foundation of China (13JJ6067).

\section{References}

[1] G. Marnier, C. Keller, L. Taleb, Fatigue of OFHC pure copper and 316L stainless steel subjected to prior tensile and cyclic prestrains, Int. J. Fatigue, 91(2016)204-219

[2] Murty KL, Charit I. Structural materials for Gen-IV nuclear reactors: challenges and opportunities. J. Nucl. Mater, 383(2008)189-195 
[3] Goyal S, Sandhya R, Valsan M, Bhanu Sankara Rao K. The effect of thermal ageing on low cycle fatigue behaviour of 316 stainless steel welds. Int. J. Fatigue 31(2009) 447-454

[4] Roy SC, Goyalb S, Sandhya R, Ray SK. Analysis of Hysteresis Loops of 316L(N) Stainless Steel under Low Cycle Fatigue Loading Conditions. Procedia Eng., 55(2013)165-170

[5] Maeng WY, Kim MH. Comparative study on the fatigue crack growth behavior of 316L and 316LN stainless steels: effect of microstructure of cyclic plastic strain zone at crack tip. J. Nucl. Mater., 282(2000)32-39

[6] Roy SC, Goyal S, Sandhya R, Ray SK. Low cycle fatigue life prediction of $316 \mathrm{~L}(\mathrm{~N})$ stainless steel based on cyclic elasto-plastic response. Nucl. Eng. Des., 253(2012)219-225

[7] Pham MS, Holdsworth SR. Change of stress-strain hysteresis loop and its links with microstructural evolution in AISI 316L during cyclic loading. Procedia Eng., 10(2011)1069-1074

[8] Pham MS, Solenthaler C, Janssens KGF, Holdsworth SR. Dislocation structure evolution and its effects on cyclic deformation response of AISI 316L stainless steel. Mater. Sci. Eng. A, 528(2011)3261-3269

[9] Ueno H, Kakihata K, Kaneko Y, Hashimoto S, Vinogradov A. Enhanced fatigue properties of nanostructured austenitic SUS 316L stainless steel. Acta Mater., 59(2011)7060-7069

[10]A. A. Ahmed, M. Mhaede, M Basha, et al., The effect of shot peening parameters and hydroxyapatite coating on surface properties and corrosion behavior of medical grade AISI 316L stainless steel, Surf. Coat. Technol, 280(2015)347-358

[11] J. L. Zhao, D. Xu, M. Babar Shahzad, et al., Effect of surface passivation on corrosion resistance and antibacterial properties of Cu-bearing 316L stainless steel, Appl. Surf. Sci., 386(2016)371-380 